\title{
Giörgy Ligeti: Concerto de Câmara para 13 Instrumentos
}

\author{
Carol Gubernikoff
}

O Concerto de câmara para treze instrumentos de Giörgy Ligeti foi composto em 1969/1970. Foi criado num momento que significa a maturação de seu estilo anterior, caracterizado por uma grande densidade de textura e harmônica, e precursor de alguns aspectos que ele virá a desenvolver posteriormente, como uma maior transparência e melodismo.

O estilo de Ligeti é absolutamente pessoal, com marcas muito características ealguns dados de sua biografia podem ajudar a esclarecer esta sua independência e sua trajetória composicional.

Ligeti chegou à Alemanha em 1957, aos 35 anos de idade, vindo de Budapeste, na Hungria. Em várias entrevistas ele teve oportunidade de narrar os acontecimentos trágicos de sua vida anterior: a perda de quase toda a família nos campos de concentração nazistas e a fuga da Hungria após a invasão soviética. Antes de chegar a Colônia, Ligeti havia tido muito pouco contacto com a música de vanguarda da época. As informações que ele tinha sobre o dodecafonismo foram lidas num livro de Jelinek, havia ouvido uma única vez, numa transmissão radiofồnica, uma peça eletroacústica de Stockhausen, Gesang der Jünglinge ( $O$ Canto dos Adolescentes), e havia tido raras oportunidades de escutar ou de ler as partituras de Schoenberg, Berg, Webern ou Stravinsky. Nem mesmo de Bela Bartók, o compositor mais importante da Hungria, eram regularmente executadas as obras mais avançadas. Mas, em seus depoimentos, ele declara que o embrião do estilo que ele viria a desenvolver já estava formado antes de ele chegar à Europa Ocidental da época. 
Em Colônia foi recebido por Stockhausen e seu maior interesse era trabalhar nos estúdios de música eletrônica. Segundo ele, esta parecia ser a técnica mais extraordinária e mais rica de possibilidades para 0 desenvolvimento da linguagem musical. Após realizar três obras no estúdio de música eletrônica da rádio de Colônia, abandonou definitivamente este projeto e passou a escrever obras puramente instrumentais e vocais. A experiência com a música eletrônica, entretanto, foi fundamental para o desenvolvimento da sua técnica de composição. Esta alia a rigorosa formação tradicional, principalmente em contraponto, do qual foi professor na Hungria, ao interesse despertado pela composição de música eletrônica em realizar superproduções de massas sonoras. Esta mistura de técnicas e sensibilidades diferentes resultará num estilo absolutamente original, inédito e pessoal.

A sua "estréia" no mundo da vanguarda não foi uma obra musical. Foi uma análise rigorosa e crítica da obra Structures de Pierre Boulez. Neste texto Ligeti opõe à concepção serialista "bouleziana" de composição três críticas fundamentais, sendo que duas chamam a atenção para a questão da confusão entre inteligibilidade e sensibilidade:

A primeira se refereà "unidade organizacional", que tomaa ordem fisica pela ordem psíquica do som. Para ele, estas duas ordens são de naturezas diferentes euma não pode ser entendida pela outra. A segunda crítica se refere à arbitrariedade de se colocar em primeiro plano a matemática, ou a ordem numérica, em detrimento do sensível. Para ele, mesmo o geométrico deve ser flexibilizado pela sensibilidade do artista. Numa entrevista a Pierre Michel ele diz:

“(...) É um filme muito bonito. São mostradas as telas de Mondrian vistas de uma certa distância, e depois de mais perto. Vemos também o ateliê de Mondrian em Nova York, antes de sua morte nos anos 40 . Havia sempre uma espécie de moldura de madeira que ele podia deslocar, mas isto não era nunca calculado.... A arte começa onde a geometria, a matemática, a especulação acabam." (in MICHEL, p. 180)

A terceira crítica diz respeito à neutralização da articulação rítmica pela equalização dos intervalos. 
O objetivo estético de Ligeti é realizar uma música estática e contínua, liberada das pulsações medidas e das notas. Para atingi-lo ele utiliza uma escrita muito detalhada, uma micropolifonia à maneira de um mundo microscópio escondido, onde tudo está em constante movimento mas cujo resultado produz um efeito de imobilidade. É uma música que deve dar a impressão de não ter começo nem fim, como ele mesmo a definiu, ela deve soar como "uma fatia dealgo que sempreexistiu". Este mundo microscópico, este "deserto populado", permanecerá como uma das marcas altamente pessoais do estilo sempre em transformação de Ligeti.

No caso do Concerto de Câmara, o mundo microscópico está sempre presente na intenção de criar uma obra a partir de um "modelo orgânico". De acordo com Pierre Michel, ele consegue realizar este crescimento orgânico através de mudanças internas sobre um material sonoro que permanece aproximadamente sempre idêntico no seu aspecto global. Os três procedimentos básicos empregados são: permutação, omissão e acréscimo de sons. De fato, o primeiro movimento, "Corrente", começa por uma permutação dos sons compreendidos no âmbito de uma terça maior $\left(\mathrm{sol}^{\mathrm{b}} / \mathrm{si}^{\mathrm{b}}\right)$, que através de transformações quase imperceptíveis em quinze etapas, cada uma com sua duração específica e irregulares entre si, dirige-se para um uníssono de mi bemol distribuído por cinco oitavas de âmbito. $\mathrm{O}$ aparecimento deste uníssono, que é sustentado por cerca de catorze segundos, é preparado por um trinado ( $\left.\mathrm{do}^{*} / \mathrm{ré}\right)$ que tem as funções de condensar e dissolver o material e preparar a sua apresentação.

Apesar de nuncater utilizado a técnica dodecafônica ou o serialismo, Ligetiadotaum atonalismo produzido pelautilização do total cromático. Para realizar o tempo musical estático, suas primeiras obras trabalharão sobreagregados sonoros orquestrais, chamados "clusters", onde todas as notas cromáticas compreendidas dentro de um determinado âmbito participam.

A partir de Lux Aeterna, peça para dezesseis vozes "à capela", Ligetiabandona gradativamenteouso exclusivo de "clusters" ese dirige para uma escrita de maior transparência e luminosidade. Em Lux Aeterna, por exemplo, predominamos agregados sonoros formados por superposições dos intervalos de segunda maior mais terça menor, que 
resultam num âmbito de quarta justa.

\section{Exemplo 1}

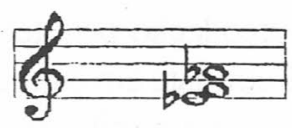

No primeiro movimento do Concerto de Câmara, cada uma das quinze etapas pode ser tanto cromática quanto diatônica. No caso das músicas de Ligeti o uso do diatonismo faz com que ele surja do cromatismo e não o contrário, ou seja, o cromatismo não é entendido nem elaborado como acidentes, ornamentos ou notas de passagem do diatonismo.

Muitas vezes a sonoridadeé diatônica e, nestes casos, a escolha dos sons em suas relações verticais é de tal feita, que o batimento entre os harmônicos dostimbres das vozes produzuma oscilação eindeterminação das alturas percebidas. A entrada de Lix Aeterna é exemplar a este respeito, as notas perdem a estabilidade e ouvem-se as vozes oscilarem literalmente, enão poruma "desafinação". Estanecessidade de produzir harmonias e timbres instáveis nasce da necessidade de se representarem sons que não têm estrutura harmônica em seus parciais, mas inarmônicas. Sons que, por questões dosmateriais com que são produzidos, defratemse em relações de proporções numéricas que não são inteiras.

Uma das conseqüências mais importantes para esta maneira de conceber e utilizar os sons, certamente influenciada pela música eletrônica, é a perda do conceito de estabilidade do sistema sonoro musical. O temperamento, no século XVIII, pela equalização dos doze sons da escala cromática em intervalos iguais, possibilitou o desenvolvimento dos conceitos de transposição e modulação. A fixação das notas em relações regulares possibilitou a identidade dos perfis melódicos e das harmonias. Ligeti, ao utilizar de maneira extensiva e contínua, por durações longas, as superposições de camadas, ao invés de neutralizar as relações intervalares, crítica que ele havia feito ao pensamento estruturalista e serial, faz ressaltar as instabilidades provocadas pelo choque entre os harmônicos muito próximos. No Kyrie do Requiem, ele mimetiza o sommetálico e oscilante de sinos. Isto érealizado pela escolha 
de notas que correspondam aos parciais do espectro inarmônico que os caracteriza. Esta técnica pode ser definida como mimetização concreta do mundo microscópico dos sons.

Ligeti tem uma especial predileção pela técnica do contraponto, principalmente a do cânon, que consiste em entradas sucessivas de uma mesma melodia. É com Webern, que o utilizou constantemente como forma de criar simetrias internas, que o cânon ganha destaque no século XX como uma das técnicas que possibilitam "misturar" ou amalgamar o nível horizontal com o nível vertical, o sucessivo com o simultâneo.

"O cânon me permite escrever melodicamente uma certa sucessão que eu quero tornar simultânea, vertical. O cânon é também o meio de desenvolver gradualmente uma simultaneidade. Eu utilizo cânones tão densos que não se ouve o tecido polifônico, mas uma homogeneidade vertical que muda incessantemente." (in MICHEL, p. 163)

Além do cânon, Ligeti utiliza freqüentemente a permutação de notas contidas dentro de um determinado campo. A constante repetição das mesmas notas estabiliza a percepção que através deste artificio não cria expectativas e pode ser conduzida através de diferentes patamares espaciais e timbrísticos. Ao invés da direcionalidade da música tonal, a multidirecionalidade.

\section{A partitura do Concerto de Câmara}

\section{O Andamento}

À primeira vista, a partitura é absolutamente convencional: compasso quaternário num tempo de semínima igual a sessenta. $O$ andamento só vai ser ligeiramente ralentado no compasso 32 , quando a semínima passa a cinqüenta, apenas por um tempo, e nos compassos 39 e 40, quando a semínima passa a quarenta. No segundo caso, trata-se de um contínuo sonoro sem pulsação que éirregularmente prolongado através 
deste expediente. Na verdade, neste local, cada mudança de "compasso" corresponde à duração específica de cada novo som que entra no espaço do âmbito do uníssono e que o preenche harmonicamente, antes da retomada do "tempo primo" com sua textura correspondente.

Há ainda diversas passagens "senza tempo", ou seja, com tempo livre, onde a indicação da duração corresponde ao tempo em segundos. Como a indicação metronômica éigual a sessenta, a contagem do tempo para os intérpretes continua regularmente, à velocidade de uma pulsação por segundo.

A preocupação com a clareza e a compreensibilidade da escrita é uma constante no trabalho de Ligeti. O compasso quaternário indicado no Concerto não tem nenhuma conseqüência do ponto de vista do resultado musical. É apenas um recurso utilizado para facilitar a leitura. Isto fica bem claro na própria partitura onde, no prefácio, Ligeti esclarece que as barras de compasso servem apenas para sincronizar as partese que não devem ser nem acentuadas, nem levadas em consideração para a acentuação métrica. Todas as entradas dos instrumentos devem ser muito suaves, imperceptíveis, e os acentos devem ser realizados apenas quando propostos, independentemente de sua localização no compasso.

\section{As "Taleas"}

A ordenação das durações e o uso das "taleas" são muito importantes para a compreensão da técnica de composição de Ligeti.

"Talea" é uma palavra grega que significa corte e, por analogia, fatia, proporção. Historicamente, pela repetição de uma determinada configuração rítmica, no moteto isorrítmico medieval, esta fatia tornaseuma proporção eum padrão. Foi muitoutilizada, antes da regularidade dabarra de compasso, nos séculos XIV XXV pelos grande compositores polifonistas. Entre estes, Ligeti tem uma especial afeição pela música de Ockeghem.

Ligeti declara adotar o sistema de taleas com muita liberdade e de uma maneira muito pessoal. Através deste artificio, seu pensamento parte da idéia de um inteiro que é submetido a divisões em diferentes proporções. Simplificando, cada unidade pode ser estriada em um determinado número de partes. Deste modo, um valor qualquer, como 
a semínima, por exemplo, pode sofrer as seguintes ações utilizadas no Concerto de Câmara:

Exemplo 2
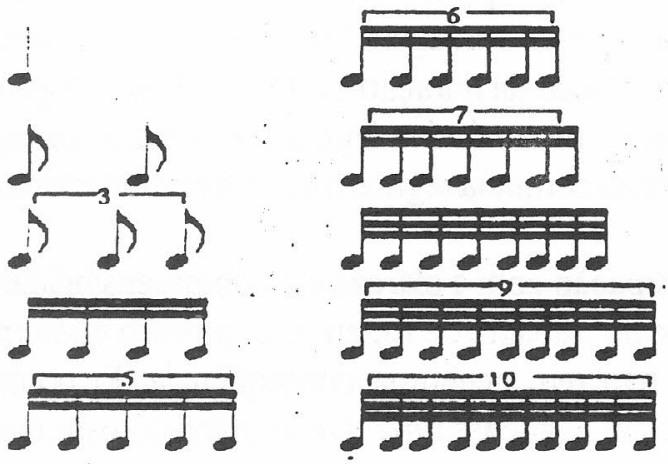

Sendo que cada uma delas pode receber diferentes configurações rítmicas, como por exemplo:

Exemplo 3
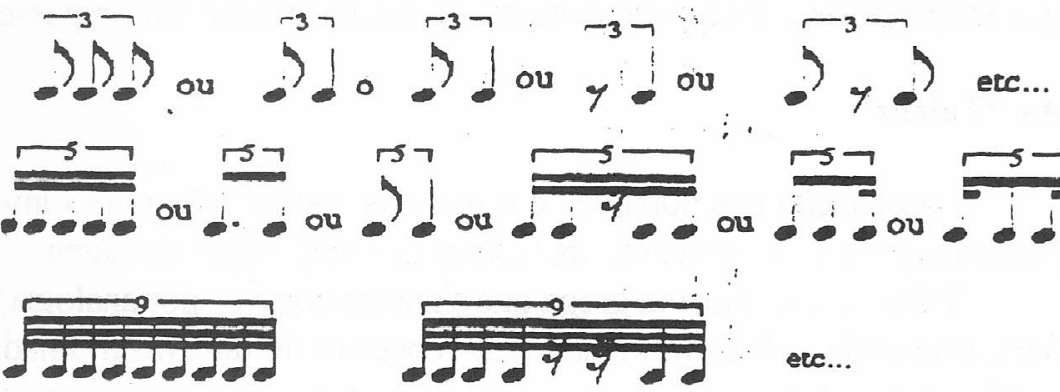

erc...

Além das articulações internas devidas aos movimentos melódicos e às ligaduras que ligam uma talea à outra. Estes deslocamentos tomam impossível o reconhecimento das proporções regulares, produzindo uma grande riqueza de relações duracionais, rítmicas e um tempo absolutamente livre.

A velocidade é outro fator muito importante para este primeiro movimento e está estreitamente ligada ao uso das taleas. A peça tem um plano bem claro de acelerações e desacelerações que são atingidas tanto pelas configurações quanto pelas velocidades das taleas. Podemos 
comparar a tabela do uso das taleas com a tabela das notas realizadas por Pierre Michel:

Exemplo 4

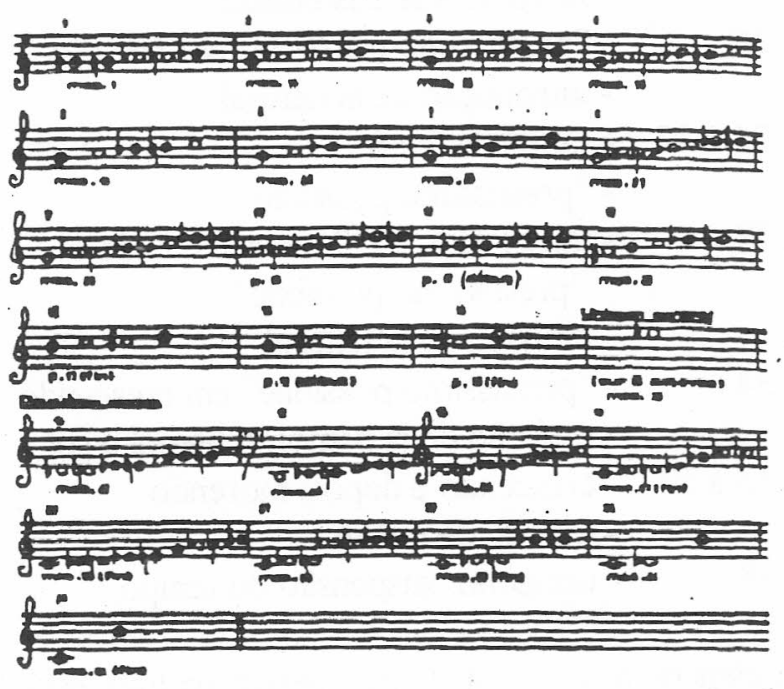

O uníssono de mi bemol, no compasso 38 , divide o primeiro movimento em duas seções. Este uníssono é para onde se destina toda a primeira seção. Isto pode ser confirmado pelo movimento melódico. O ré surge como ornamento, trinado de do e se torna a sensível de mi bemol.

O uso das taleas confirma a direcionalidade de toda a primeira seção:

comp. 1 a 5 - taleas de $3,4,5,6$ e 7

comp. 6 e 7 - aceleração

- taleas de 7,8 e 9

comp. 8 a 17 - taleas de 3,4 e 5

- no compasso 14.4 introdução do si natural na trompa

comp. 18 e 19 - aceleração

- taleas de 8, 9 e 10

comp. 20 e 21 - "senza tempo", "prestissimo possibile"

- introdução de do natural e omissão de sol bemol

comp. 22 a 24 - "prestissimo possibile" e taleas de 8, 9 e 10 


$\begin{array}{ll}\text { comp. } 25 & \text { - "prestissimo possibile" com acorde sustentado } \\ \text { comp. 26 a 29 } & \text { - todas as taleas de } 3 \text { a } 10 \\ & \text { - novo acorde sustentado } \\ \text { comp. 30 } & \text { - "prestissimo possibile" cordas } \\ & \text { - introdução de lá natural } \\ \text { comp. 31 e 32 } & \text { - taleas de } 5 \text { e } 6 \\ & \text { - "prestissimo possibile" } \\ \text { comp. 33 } & \text { - taleas de 5, 6 e } 7 \text { em acelerando e } \\ & \text { "prestissimo possibile" } \\ \text { comp. 34 } & \text { - omissão de lá natural } \\ \text { comp. 35 a 37 } & \text { - omissão de lá bemol, si bemol e sol } \\ \text { comp. } 38 & \text { - trinado de do } / \text { ré } \\ & \text { - uníssono, suspensão do tempo }\end{array}$

A idéia ou princípio de talea, medida, padrão, está presente tanto para as durações como para as alturas. As alturas serão conduzidas ou conduzirão a percepção dentro de determinados padrões de âmbitos diferentes, que serão preenchidos por vezes cromaticamente, por vezes diatonicamente. A distribuição das durações dentro das taleas também obedecerá a dois princípios que, por analogia, poderemos chamar de cromáticos e diatônicos.

Cromáticas são, por exemplo, as distribuições mais "estreitas", como:

Exemplo 5

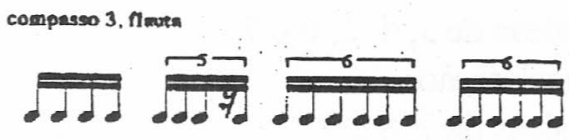

ov compasso 7 , oondas
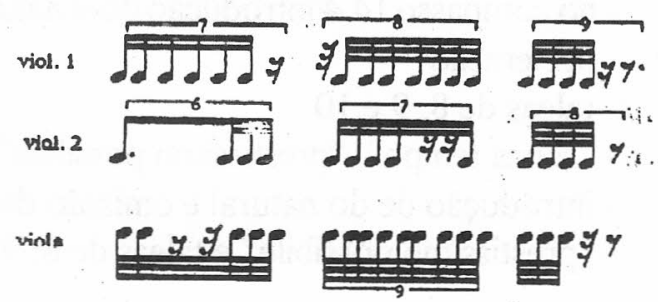
e diatônicas, as distribuições mais "largas":

Exemplo 6

compasso 9.3, entrada das cordas

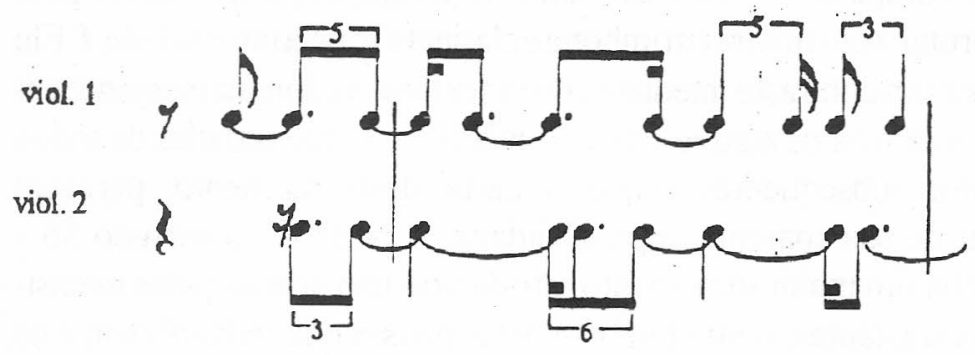

Sons longos e sustentados

Como não existe a noção de melodia acompanhada e o espaço harmônico não tem direção definida, as notas longas e sustentadas vão cumprir várias funções.

No compasso $14 / 15$, a primeira nota longa a aparecer é o si natural na trompa. Ela começa imperceptível, sem ataque, e, crescendo pouco a pouco, esboça um embrião de melodia. É a primeira nota a ser introduzida no "cluster" da "exposição". Ela emerge do cânon duplo das cordas.

No compasso 25, inicia-se um acorde para contrabaixo, trompa, clarinete e flauta, que penetra sem ataque em pianíssimo e confirma a cadência "senza tempo" das cordas sobre sol, lá, si bemol e dó. Este acorde sofre uma mutação timbrística passando para contrabaixo, violoncelo e viola, no compasso 28 . Os dois violinos se encarregarão de introduzir dó" e ré no compasso 30 , que aos poucos se dissolverão na cadência "senza tempo" das cordas. Este processo conduz ao uníssono do compasso 38 .

O grande uníssono do compasso 38 ressoa e repercute todos os sons longos e sustentados do movimento. Ele tem função de (anti?) ponto culminante, que suspende todos os eventos. Este uníssono será preenchido e distorcido por um acorde que entra "senza tempo" e que vai lenta e progressivamente granulando a textura do uníssono, que se estenderá até o compasso 50. 
A segunda seção do primeiro movimento usa predominantemente taleas cromáticas de 7, 8 e 9 e cadências livres. Isto produzirá um efeito de aceleração em relação à primeira parte.

No compasso 54 acontece um som longo, importantíssimo pelo ataque brutal, pelo timbre (trombone clarinete) e pela intensidade, $\mathbf{f}$. Ele estabelece um contraste imediato com a textura predominantemente em p, que contamina os ataques, as velocidades e as intensidades de todos os eventos subseqüentes e que, a partir deste momento, parecem despertar de sua aparente impassibilidade. A partir do compasso 56 a peça ganha um maior movimento, produzido não apenas pelas intensidades contrastantes, como também pelas pausas que redistribuem e os eventos nas suas diferentes velocidades, até um ralentando "diatônico" final.

\section{Melodias}

Existem alguns esboços de melodias que mal conseguem emergir da densidade do complexo sonoro. Logo no compasso 1, o violoncelo enuncia um fragmento melódico que é amplificado em extensão e âmbito pelo clarinete baixo.

Exemplo 7

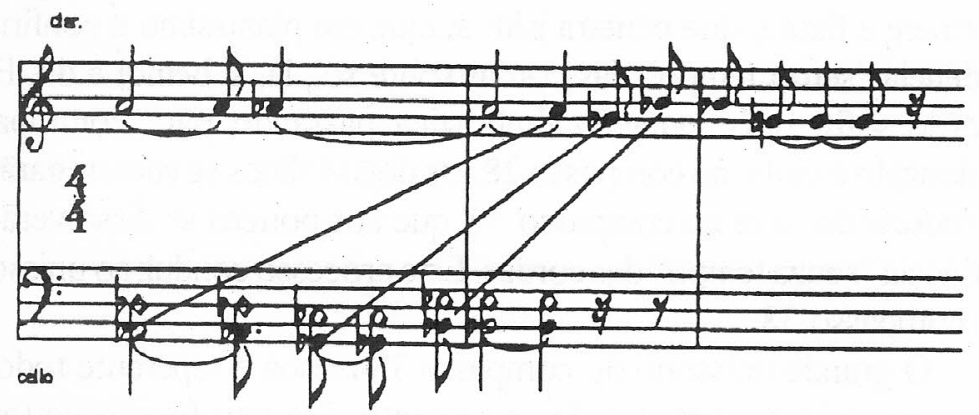

No compasso 4, a melodia enunciada pela trompa recebe uma imitação melódica, mas não rítmica, no clarinete baixo e no oboé. 
Exemplo 8

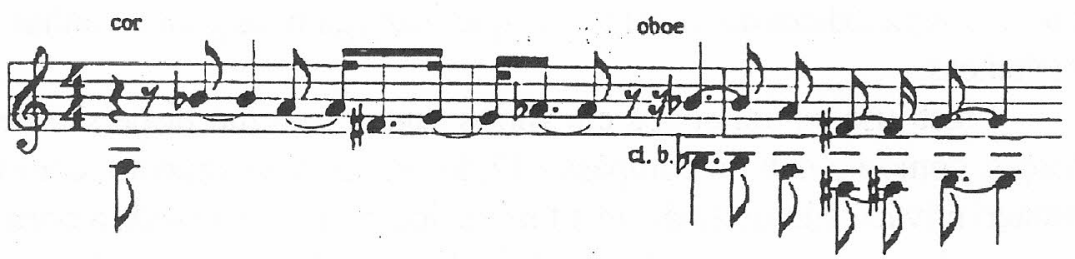

E, finalmente, no compasso 49 , uma melodia forte nos sopros se impõe pelo timbre em uníssono e pela extensão. É esta melodia que prepara e possibilita o aparecimento do mi, brutal, do trombone no compasso 54.

Exemplo 9

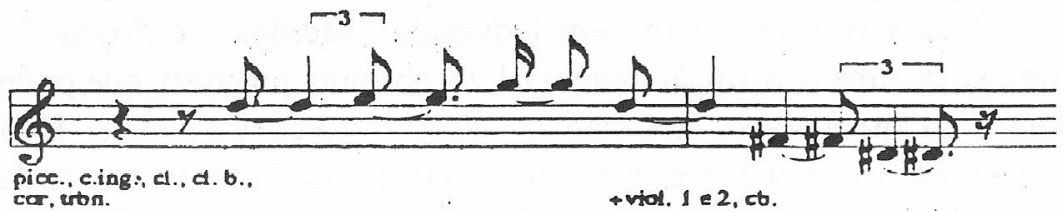

Estas pequenas melodias funcionam como uma lupa de aumento dos movimentos internos do corpo granulado do primeiro movimento. Estas granulações produzem, numa microescala, diversos movimentos melódicosimpostos pela permutação das notas num âmbito restrito. São estes movimentos internos amplificados que se tornam os esboços de melodias.

\section{O uníssono e o terceiro movimento}

O uníssono tem uma função importantíssima nesta obra de Ligeti. Apesar de ser uma consonância perfeita, o seu uso na literatura ocidental não é muito freqüente, a não ser como resolução de tensões, nas conclusões de cadências. Alban Berg inaugura um uso extremamente expressivo do uníssono no terceiro ato da ópera Wozzeck, onde as mudanças de timbre e de intensidade num espaço "liso" se encarregam de portar todos os sentidos. Este estaticismo profundo, e que revela um movimento e uma .... internos do som, é um dos exemplos de sua 
capacidade de concentração expressiva, sem mencionar os grandes uníssonos melódicos do romantismo, que "carregam" as grandes linhas melódicas.

Ligeti usa os uníssonos em vários sentidos: como dispersão de forças, como no mib do compasso 37 do primeiro movimento; como espaço privilegiado de amálgama timbrística, ao longo de toda a obra; e como elemento concentrador e catalisador, que desencadeia as forças. O uso mais notável de concentrador de forças está no terceiro movimento, que tem um caráter completamente diferente do primeiro.

\section{Mecânico e Preciso}

O terceiro movimento vem indicando "Mecânico e Preciso". Trata-se de uma construção maquinal, de absoluta precisão, que pode lembrar os instrumentos automáticos, como o realejo e a pianola. Esta atração pelo mecânico se expressa na admiração de Ligeti pela obra de Conlon Nancarrow, compositor norte-americano radicado no México. Este compositor tem uma obra extensa para pianola, composta diretamente nos rolos que vão acionar as teclas. Através deste recurso "sobrehumano", as obras atingem grande velocidade de execução e uma simultaneidade de vozes e ritmos impossíveis de serem realizadas por intérpretes.

\section{As seções}

A primeira seção, do compasso 1 ao 11, caracteriza-se por uma nota repetida em todos os instrumentos que, em entradas sucessivas, um "sforzando" seguido de pianíssimo, resultará numa configuração rítmica complexa nas durações e granulada no tempo timbrístico. Nestas entradas, o procedimento é exatamente o contrário daquele do primeiro movimento. Sobre o tecido granulado produzido pelas "taleas", as entradas perceptíveis estabelecerão a rítmica complexa, que funciona como um relevo em relação à trama de fundo.

A "nota ripettuta" é uma ornamentação típica do barroco italiano. Aqui ela tem a mesma função: ornamentar, estriar a duração de um som 
longo. Mas, desbordando o caráter ornamental, ela conforma o corpo sonoro temporal da obra pela riqueza e variedade de durações e pela distribuição de cada elemento.

A exposição é feita pelos sopros sobre a nota mi. Cada "grupo" tem uma extensão diferente da mesma talea de 8.0 resultado rítmico é:

\section{Exemplo 10}

movimento III. comp. 1-2.

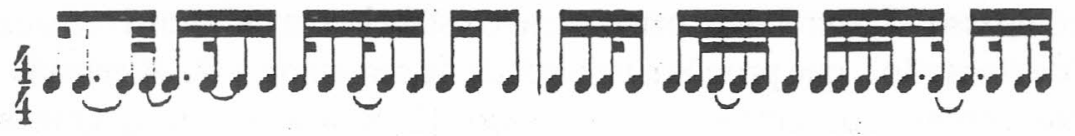

que corresponde à distribuição da seguinte partitura:

Exemplo 11

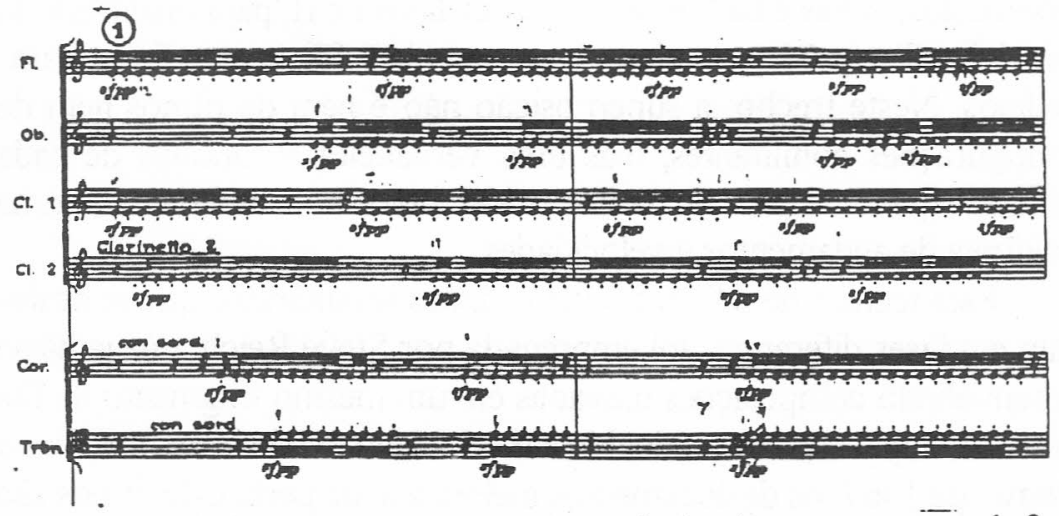

A partir do compasso 3, coma entrada do piano em anacruz de fusa, começam a ser introduzidas dissonâncias rítmicas e melódicas, sempre em relação de proximidade, tanto nas alturas como nas taleas. Um "cluster" rítmico e melódico produz gradativamente um glissando descendente, que mimetiza os glissandos da música eletroacústica, seja pelo timbre granulado, seja pelos movimentos, seja pelas velocidades. $O$ máximo de atividade é atingido nos compassos 5 e 6 e, em seguida, vai gradativamente perdendo forças até o compasso 11.

A segunda seção começa por um novo uníssono sobre lab, com notas repetidas, desta vez "senza tempo", o mais rápido possível, com 
ataques secos e precisos. As novas notas, ao serem introduzidas uma a uma no tecido granulado, tecem uma espécie de perfil melódico, que se mistura gradativamente ao "cluster" construído. Um novo glissando, extenso elentíssimo, percorre o espaço harmônico e permanece ao longo da terceira seção, que começa no compasso 32.

A partir do compasso 32, sobrepõe-se ao tecido granulado o tecido estriado das cordas em pizzicato, com pulsações evelocidades diferentes e simultâneas. As duas camadas vão sobrepor-se, cada uma com sua textura, configuração e tempo próprios, até o compasso 40. A partir do compasso 38 , entretanto, piano e cravo estabelecem uma nova camada "de transição", que propõe a velocidade de semínima = 66. A camada das cordas, que entrou no coinpasso 32, apresentou uma grande oscilação de andamentos, ou seja, a velocidade de desenvolvimento não possui uma medida estável. Ela começa por semínima $=60$, passa sucessivamente a 72, 56, um "divisi" de velocidades em 56 para violoncelos, violas e baixos, e 60 para violinos I e II, para finalmente se "estabilizar" em 66 para piano e cravo sobre 60, que se fixou para violinos. Neste trecho, a superrosição não é nem de ritmos nem de configurações conflitantes, mas uma verdadeira autonomia de cada camada, que avança e recua nas velocidades, nos andamentos: uma polifonia de andamentos e velociuiades.

Esta técnica de diferentes velocidades simultâneas, que se deslocam em fases diferentes, foi empregada por Steve Reich, que já havia desenvolvido composições baseadas em um mesmo fragmento da fita gravada, duplicado e reproduzido em velocidades diferentes. Em Piano Phase, de 1967, os deslocamentos melódicos, de perfil e de ritmos são produzidosúnica e exclusivamente pelas mudanças de velocidade de um mesmo desenho elementar. Nesta peça, dois pianistas devem controlar os andamentos comuns, os individuais e próprios, eretornar aos comuns. Como são sempre as mesmas notas que são obsessivamente repetidas, a perda de referência espaço-temporal é inevitável. A idéia de fases, relativas às velocidades dos parciais de um som, é deslocada para o universo "macro" dos sons já determinados em um sistema e elaborada "à maneira de" batimentos no nível do sensível. No caso do tratamento "em fases" que Ligeti desenvolve para as diversas camadas em suas velocidades próprias, cada uma delas é extremamente complexa em si 
mesma e já contém, no nível "molecular", as superposições de taleas.

O compasso 41 retoma o mesmo tecido granulado do "senza tempo", desta vez pelas cordas, que iniciam novo glissando lentíssimo de "cluster". No compasso 42, uma camada formada por contrabaixo, piano, trombones e trompas, distribui um uníssono de sib por taleas sobrepostas, respectivamente de $5,7,4$ e 3 , à velocidade de semínima $=60$.

A partir da letra $\mathrm{J}$, compasso 46 , nova polifonia de andamentos. Acrescentam-se às duas camadas um "Più Mosso", à velocidade de 80 para piccolo, oboé, clarinete 1 e 2, e cravo. Esta camada deve mascarar as outras, porque ela é em ff na região aguda e sobre um "cluster".

A partir do compasso 48 há um ralentando para todas as camadis, chegando a uma superposição de 60 sobre 40 . Todo este tecido é lentamente desfeito, como se cada fio da trama estivesse sendo puxauo, até a retomada por uma coda, "tempo primo" (semínima=60 ralentando até 40), que começa no compasso 60. Assim como para o primeiro movimento, o trinado volta a ter uma função importante. É sobre una camada aguda de trinados, para piccolo e clarinetes 1 e 2, que os ataq: 'es esparsos, sequíssimos e furtíssimos, de todos os outros instrumenios reforçam a idéia de fixidez eestabilidade através da utilização sempre das mesmas notas de uma díad de segunda maior (réb/mib). De todas us propostas, a que é mantida para a "conclusão" é a idéia timbrísticosonora do pizzicato, que dominou todo o terceiro movimẹto, que é "reforçada" ou "confirmada" na coda.

Desde 1962, quando compôs Poème Elétronique para cem metrônomos, Ligetitem manifestado sua predileção especial pelosjogos mecânicos, pulsativos eregulares. A simultaneidade decem metrônomos produzia uma grande complexidade de pulsações.

No caso do Concerto de Câmara, assistimos à maestria na manipulação dos tempos, durações e proporções que mimetizam mecanismos, mas que estão a serviço da expressão e da ilusão. Principalmente no terceiro movimento funciona uma "ilusão de acústica", em analogia com a ilusão de ótica, onde o extremo rigor da escrita produz efeitos inesperados e "irracionais", principalmente na percepção temporal. Pierre Michel chama a técnica de Ligeti de "caos organizado". Deleuze diria um "Caosmos", onde o caos não se opõe ao cosmos, a desordem 
à ordem, mas produz, na sua força múltipla de determinação/ indeterminação, um universo.

Este universo é, sem dúvida, um universo simulado. Da mesma maneira que Ligeti simula a música criada através da experiência da tecnologia eletrônica - e é por isso que ele não precisou mais compor eletronicamente -, ele estende a noção de simulação para o universo orgânico e para o mecânico. Desta feita, pelo menos três níveis de simulação são encontrados numa música que, paradoxalmente, parece "retomar" o uso de instrumentos tradicionais: o mecânico, o orgânico e o eletrônico. Além destas simulações encontram-se a simulação instrumental, através da pesquisa com os espectros de timbre, e a mais profunda de todas as simulações, a da vida interna do som, com suas instabilidades e oscilações. A manipulação do "tempo interno" de um som que aflora à superficie sensível é realizada a dois níveis principais: o timbrístico, pela simulação do espectro sonoro, e o mais "temporal", propriamente dito, pela superposição das diferentes velocidades das fases.

Do ponto de vista macroformal, os procedimentos também mimetizam uma linearidade que não se concretiza de forma convencional. Os pólos de atração, para onde se dirigem as "linearidades", são locais emultiplicados pela densidade de direções possíveis do "cluster" que a falsa linearidade se revela uma multidirecionalidade.

A relação com o contínuo, entretanto, permanece a mesma. A "fatia de alguma coisa que já estava lá" é realizada pela "extração" de uma superfície em relação ao "Caosmos", que é sempre mais denso e virtualmente mais expressivo que o sensível. Desta forma, a pulsação nasce do não-pulsativo, o diatonismo do cromatismo, o sensível do não-sensível, entendido não como ideal, mas como concretude sonora e universo simulado. Este tecido, tramado por Ligeti, torna-se objeto de ampliações de onde são extraídas camadas cada vez ainda mais aumentadas, como as melodias que já estão "contidas" nas permutações das tramas e as notas longas, que criam falsas estabilizações temporárias. 